\title{
Desertification and Its Control in China
}

By Ci Longjun, Yang Xiaohui. Higher Education Press of China, 2010, 513 pages, 89.00Yuan RMB.

The term desertification was first used by Lavauden in 1927; from then on, more than one hundred definitions on desertification have appeared in the literature. The definition of desertification given by the United Nations Convention to Combat Desertification (UNCCD) is the land degradation in arid, semiarid and dry sub-humid areas resulting from various factors, including climatic variations and human activities. Desertification not only reduces the biomass production, but also impairs decomposition process, and even interrupts the circulation of materials and energy flow. Desertification as the changing of productive land into a desert as the result of ruination of land by maninduced soil erosion, has been proceeding worldwide. At present, about more than 100 countries on six continents and one-fifth of the world's total population are affected by desertification. Desertification throughout the world is expanding at an annual rate of 0.5 million $\mathrm{km}^{2}$. Research has shown that desertification brings harmful environmental effects not only on the area it happens, but also the areas near to and even far away from it. Thus, effective control of desertification and restoration of ecosystem health so as to realize sustainable development has become a urgent and common mission of humanity.

As in the world, desertification is one of the most severe environmental problems in China. China as a developing country with a large population and scarce arable land, feeds 22 percent of the world's population on seven percent of the world's tillable land. However, long term over cultivation has become the most dominant cause for desertification in China. China presently has $262.2 * 10^{4} \mathrm{~km}^{2}$ of desertified land and still is increasing at the rate of $2460 \mathrm{~km}^{2}$ per year. The total area of desertification affected land approximately occupies $27.32 \%$ of the total land territory, or $79.1 \%$ of the total areas of arid, semi-arid and dry sub-humid areas. In China, desertification affected lands are mainly distributed in the Northwest, North and the Northeast, where some of the most underdeveloped counties are located. Desertification worsens ecological environment, accelerates further poverty and invades the survival space of Chinese people. It is estimated that a populations of 400 million is being threatened by desertification, and the annual direct economic loss caused is approximately 6.5 billion US Dollars. Desertification and desert expansion have become a bottleneck for sustainable development in the dry lands of China.

Different from other books available on the topics of desertification in China, the newly published book Desertification and Its Control in China attempts to cover some key topics related to desertification, especially focussed on the desertification pattern and its practical control. The book comprehensively discusses the situation of desertification in China in terms of its formation, distribution, development and prevention and control methods. The book introduced the basic theory and control methods of desertification, especially the numerous results from research carried out for the UN Convention to Combat Desertification, which hopefully will provide some guidelines for prevention and restoration for desertification in China or other areas or countries with similar conditions. The main contents of the book include: 1 Concept and global status of desertification; 2 Natural background of drylands of China; 3 Natural resources and their utilization in the drylands of China; 4 Sandy deserts, Gobi, sandlands and sandified land in dryland; 5 Water erosion in the drylands of China; 6 Soil salinization; 7 Steppe degradation and rehabilitation in Northern China; 8 Biological and technical approaches to control windy desertification; 9 Engineering and technological measures for combating desertification; 10 Optimized sustainable eco-production paradigms in drylands.

This book will become a good reference for the persons who are engaged in research work on desert or desertification, and restoration ecology or ecological engineering, forestry, agriculture and environmental science, etc, as well as teachers and students who major in the relevant fields, or any other persons who are interested in these fields.

Li DeZHI ${ }^{1}$ and QIN AILI ${ }^{2}$

${ }^{1}$ Lab of Urbanization and Ecological Restoration of Shanghai; National Field Observation and Research Station in Tiantong Forest Ecosystem of Zhejiang; Department of Environmental Science, East China Normal University, 3663, Zhongshan Rd (N). Shanghai, China. 20006

${ }^{2}$ Shanghai Vocational and Technical College of Agriculture and Forestry, 658 Zhongshan 2 Rd. Songjiang, Shanghai, China. 201600. 


\section{Erratum The Canadian Field-Naturalist 126(4)}

In response to the review of Contributions to the History of Herpetology. CFN 126(3): 344-345, the book's editor Kraig Adler pointed out (personal communication to FRC 12 May 2013): "Only one small correction. Mrs. Martof used a kitchen knife, not a gun. She told the police she slipped while cutting some pizza. But Bernie was stabbed up under his rib cage several times!"

\section{Erratum The Canadian Field-Naturalist}

It has come to our attention that sections of many of the book reviews by Li Dezhi and Qin Aili were copied from sources without attribution. The journal and the authors apologize for this oversight. 